\title{
Multilocular cystic renal neoplasm-low malignant potential (MCRN-LMP) - review
}

\author{
Sunil Vitthalrao Jagtap
}

Cite this article: Jagtap SV: Multilocular cystic renal neoplasm - low malignant potential(MCRN-LMP) - review. Ann Urol Oncol 2020; 3(2): 97-102. https://doi. org/10.32948/auo.2020.12.31

\footnotetext{
1. Department of Pathology, Krishna Institute of Medical Sciences, Deemed University, karad-415110, Maharashtra, India.

Correspondence: Sunil Vitthalrao Jagtap (Department of Pathology, Krishna Institute of Medical Sciences, Deemed University, karad-415110, Maharashtra, India; Email: drsvjagtap@gmail.com).
}

Key words Cystic renal tumors, renal multilocularcysts, renal neoplasm of low malignant potential, histopathology 


\section{Introduction}

The cystic renal neoplasms in adults are a heterogeneous group of tumors with characteristichistogenesis, radioimaging, pathological findings, immunohistochemistry and variable biological profiles. The recent advances in cytogenetics and molecular biology have provided unique processes involved in the pathogenesis of a number of renal cystic diseases in adults [1,2].

The renal cystic disease is a common cause of end stage renal disease in adults. It comprises a wide spectrum of hereditary, acquired, developmental, and neoplastic conditions [3]. These are classified in adult as:

Renal Cystic Diseases in Adults

a) Hereditary diseases - Autosomal dominant polycystic kidney disease, Medullary cystic kidney disease, Von Hippel-Lindau disease,Tuberous sclerosis complex etc.

b) Nonhereditary disease -Acquired cystic kidney disease, Medullary sponge kidney, Multicystic dysplastic kidney, Localized renal cystic disease.

They are associated with the development of a wide spectrum of benign and malignant renal neoplasms.

The terminology has changed and so called "multilocular cystic renal cell carcinoma" is currently named as multilocular cystic renal neoplasm of low malignant potential in the International Society of Urological Pathology Vancouver Classification of Renal Neoplasia and the 2016 World Health Organization revised Classification of Tumors of the Urinary System and Male Genital Organs $[4,5]$.

\section{Multilocular cystic renal neoplasm-low malignant potential (MCRN-LMP)}

From various new publications studies, the data showed excellent prognosis is related to this entity and in 2016, WHO published a new classification of renal tumors, these tumors are now termed as "MCRN-LMP" with ICD code-8316/1 [5]. Use of "Multilocular Cystic Renal Cell Carcinoma" is considered obsolete.

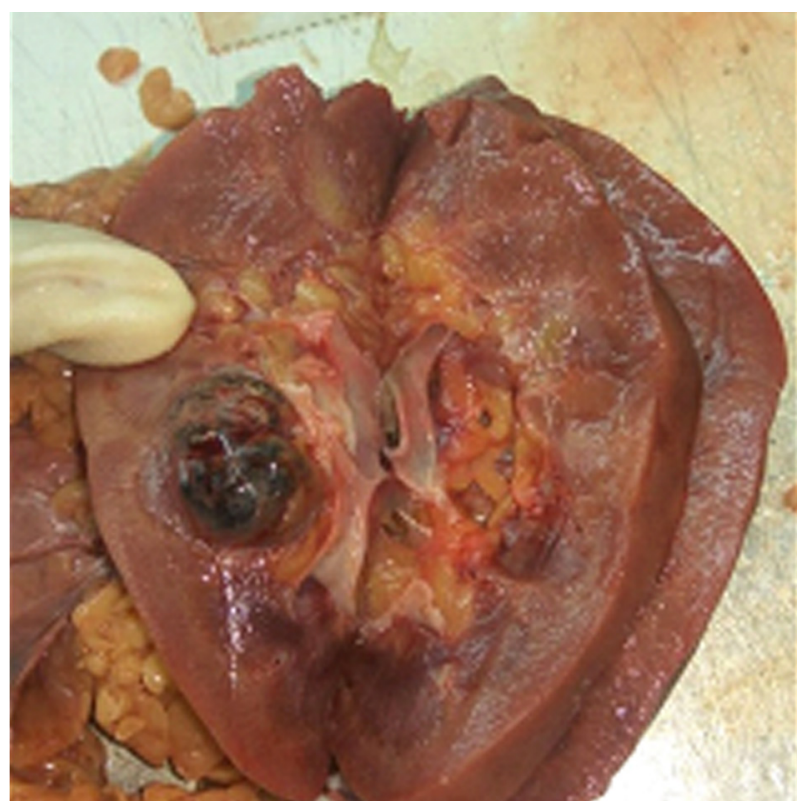

Figure 1. Gross appearance multilocular cystic neoplasm of low malignant potential: Left radical nephrectomy specimen showing a gray-brown cystic lesion surrounded by a fibrous wall.
The WHO 2016 has defined the criteria proposed for MCRNLMP in revised classification are as follows:

a) Tumor containing numerous cysts with low grade tumor cells in it (ISUP-International Society of Urological Pathology/WHO grade $1 / 2$ ).

b) Cysts are lined by single layer of tumor cells with abundant clear cytoplasm of low grading.

c) Septa contain few groups of clear cells without expansile growth [5].

The MCRN-LMP accounts for approximately 1 to $2 \%$ of all renal tumors [6]. It is included in the group of tumors of undetermined malignant potential with low nuclear grade. The male to female ratio for MCRN-LMP is 3:1 and the mean age is of 51 years.

\section{Radio Imaging}

It is noted that, clinically about $90 \%$ cases are discovered incidentally on radiology for other purposes. Contrast-enhanced ultrasound have the same sensitivity and high specificity as contrast-enhanced computed tomography for the detection of multilocular cystic renal neoplasm of low malignant potential. The ultrasonography and CT images obtained in the study by Kim et al showed that MCRN-LMP appeared as a well-defined multilocular hypodense cystic mass filled with serous or hemorrhagic fluid, with no expansile solid nodules in the thin septa may with dystrophic calcification [7].

The imaging patterns of MCRN-LMP are variable. The various studies revealed correlation between the gross pathologic appearance of the tumors with the corresponding imaging appearance.

The radioimaging various renal lesions mimics for MCRN-LMP includes hemorrhagic cysts, localized cystic disease of the kidney, atypical cysts, cystic nephroma, tubulocystic carcinoma, papillary RCC, extensively cystic RCC and other subtypes of RCC.

Most MCRN-LMPs are Bosniak category III, some are category IIF (more fluid, minimal solid component), and others are category IV (large amount of enhancing fibrous tissue). It has been observed that the correlation did not persist for tumors smaller than $3 \mathrm{~cm}$. In such situation histopathological study plays important role in confirmatory diagnosis with added immunohistochemistry and molecular evaluation.

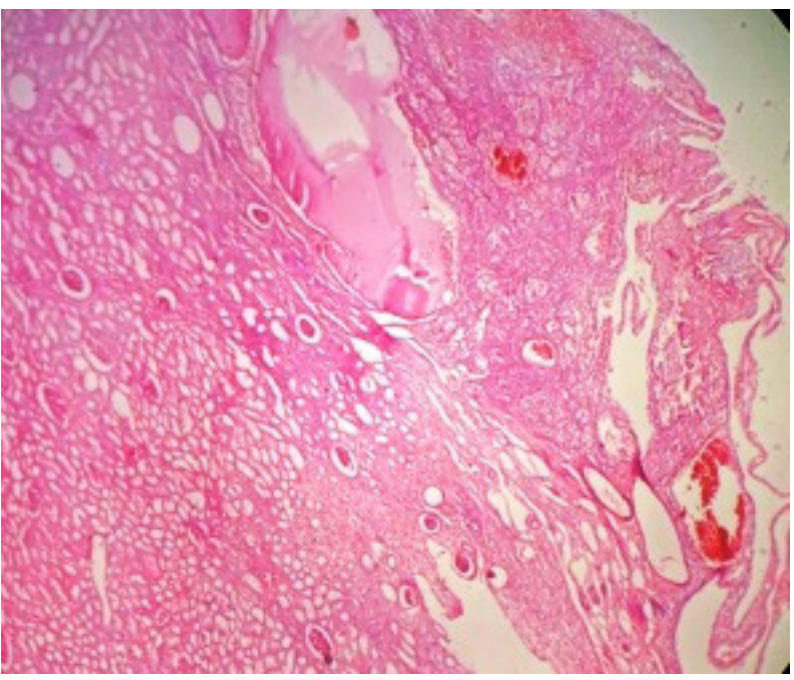

Figure 2. Renal tissue showing numerous cysts, the septa contain low grade tumor cells in it, (H \& E Stain, 40x). 
Table 1. MCRN-LMPand other cystic lesions of kidney: clinical, histopatological, IHC, and molecular features.

\begin{tabular}{|c|c|c|c|}
\hline Renal Cell Tumor types & Clinical Features & Histopathlogical/Immunohistochemical Features & Molecular Features \\
\hline \multirow[t]{2}{*}{ MCRN-LMP } & $\begin{array}{l}\text { Asymptomatic, } \\
\text { excellentprognosis }\end{array}$ & $\begin{array}{l}\text { Numerous cysts lined by clear cells; positive for } \\
\text { CAIX and CK } 7\end{array}$ & $\begin{array}{l}\text { VHL mutation, } \text { Ch } 3 p \\
\text { deletion }\end{array}$ \\
\hline & Children & & \\
\hline Cystic nephroma & $\begin{array}{l}<5 \text { years } \\
\text { asymptomatic, } \\
\text { may have } \\
\text { abdominal mass } \\
\text { or obstructive } \\
\text { symptoms }\end{array}$ & $\begin{array}{l}\text { shows variably sized cysts lined by flat / cuboidal / } \\
\text { hobnail cells with thin fibrous septae lined by bland } \\
\text { non clear cells. The ovarian-type stromal cells are } \\
\text { positive for ER, PR and CD10 epithelial cyst lining } \\
\text { positive for HMWCK, CK19 and AMACR }\end{array}$ & $\begin{array}{l}\text { DICER 1gene } \\
\text { mutations is well } \\
\text { established in } \\
\text { paediatriccystic } \\
\text { nephroma }\end{array}$ \\
\hline $\begin{array}{l}\text { ccRCCwith cystic } \\
\text { changes }\end{array}$ & good prognosis & $\begin{array}{l}\text { Numerous cysts lined by clear cells } \\
>75 \% \text { cystic are as with expansile growth }\end{array}$ & $\begin{array}{l}\text { miR-122, miR-124- } \\
\text { 3p, miR-137, miR-141, } \\
\text { miR-182-5p, miR-203, } \\
\text { and miR-217 }\end{array}$ \\
\hline Cystic PRCC & $\begin{array}{l}\text { TYPE 1- better } \\
\text { prognosis }\end{array}$ & $\begin{array}{l}\text { Papillae are lined by a single layer of cells with } \\
\text { scanty basophilic cytoplasm and low nuclear grade }\end{array}$ & $\begin{array}{l}+7,+17 \text { and other } \\
\text { trisomies, MET } \\
\text { mutations }\end{array}$ \\
\hline Tubulocystic RCC & $\begin{array}{l}\text { Mostly in Males, } \\
\text { mean age } 60 \text { years, } \\
\text { indolent course }\end{array}$ & $\begin{array}{l}\text { Dilated tubules with a single layer of cellslining by } \\
\text { cells showing nuclear enlargement. Tumor cellsshow } \\
\text { oncocytic change with hobnailing and nucleolar } \\
\text { grade of } 3\end{array}$ & $\begin{array}{l}\text { Gain of Ch } 7 \text { and 17, } \\
\text { loss of Ch Y }\end{array}$ \\
\hline ACD-associated RCC & $\begin{array}{l}\text { End-stage renal } \\
\text { disease or ACD, } \\
\text { indolent }\end{array}$ & $\begin{array}{l}\text { Eosinophilic cytoplasm, sieve-like pattern, } \\
\text { intratumoral oxalate crystals; positive for AMACR } \\
\text { and CD10, negative for CK } 7\end{array}$ & $\begin{array}{l}\text { Gain of } \mathrm{Ch} 3,16 \text {, and } \\
\mathrm{Y}\end{array}$ \\
\hline
\end{tabular}

MCRNLMP -Multilocular cystic renal neoplasm of low malignant potential, Ch-Chromosome, miR-microRNA, ACD- acquired cystic disease, RCC- Renal Cell Carcinoma. VHL-von Hippel Lindau, Cystic PRCC-Cystic Papillary RCC.

\section{Pathological features}

On the gross pathologic features- MCRN-LMPs are encapsulated, multilocular cystic appearance, variably sized cysts filled with clear, serous, gelatinous material or hemorrhagic debris, absent expansile nodules, and absent tumor necrosis (Figure 1). Before making a diagnosis of MCRN-LMP, the tumor should be extensively sampled.

The microscopic features of MCRN-LMP include cysts lined by cuboidal clear cells or flattened epithelium with septa containing aggregates of epithelial cells with clear cytoplasm and of low WHO/ISUP nuclear grade 1 or 2 (Figure 2, 3). The septae may be lined by multilayered clear cells. The capillary vessel proliferation under epithelium are important features of MCRN-LMP [8]. The solid expansile mass-forming areas by definition are absent. In few cases, cysts lining may show multilayering and few papillary feature. The septa may contain calcification, ossification, and or capillary proliferation (Figure 4). There is no evidence of necrosis, vascular invasion or sarcomatoid change.

We reported a case of MCRN-LMP in a 70 year male with history of intermittent left flank pain and hematuria. On histopathology, the left renal lesion showeda multicystic tumor, and the cysts were separated by thin fibro-collagenous septa lined by aggregates of clear cells with low nuclear grade-1 with no expansile growth [9]. On regular follow up it has been noted that there was no recurrence or metastases in this case.

\section{Differential diagnosis}

The various conditions like cystic nephroma, ACD-associated RCC, cystic papillary renal cell carcinoma, tubulocystic carcinoma, regressing clear cell renal cell carcinoma (ccRCC) with cystic degeneration should be kept as histopathological differential diagnoses [10].

Cystic nephroma shows variably sized cysts with thin fibrous septae lined by bland non clear cells. The ovarian-type stromal cells are positive for ER, PR and CD10 (Table 1).

Another differential is kept is tubulocystic carcinoma. On histopathology it shows regular, small to medium sized tubules may cystically dilated linedby high nuclear grade tumor cells. The tumor cells show oncocytic change with hobnailing and nuclear grade of 3 with prominent nucleoli. The intervening septa are fibrotic. The monolayered flattened or hobnail epithelial cell lining and presence of cellular stroma with or without tubules in the septae in tubulocysticRCC differentiate them from MCRN-LMP. These cells expresses CD10, AMACR and sometimes CK7 and HMWCK with less than half expressing CAIX.

The MCRN-LMP should be differentiated from regressing ccRCC with cystic degeneration, which often has cysts filled with hemorrhage, necrosis and hemosiderin deposits; may have extensive hyalinization and often has areas of expansile growth of neoplastic cells.

In cystic papillary RCC- Papillary architecture with fibrovascular cores containing foamy macrophages, psammoma bodies and hemosiderin is important to diagnose this type. In Type 1 PRCC, the papillae are lined by a single layer of cells with scanty 


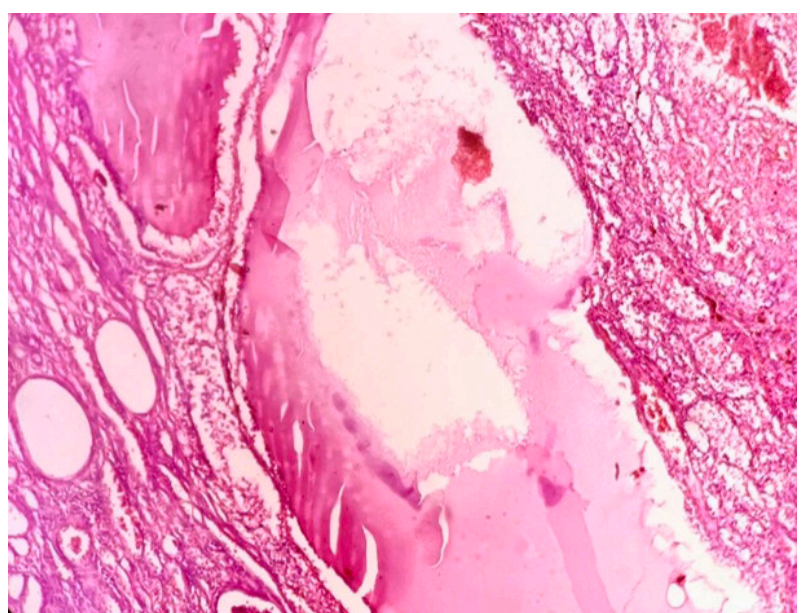

Figure 3. Renal cysts with septa containing tumor cells with abundant clear cytoplasm of low nuclear grade (H \& E Stain, 100x).

basophilic cytoplasm and low nuclear grade while in Type 2 PRCC papillae are lined by pseudostratified layers of cells with more abundant eosinophilic cytoplasm and higher nucleolar grade. Tumor shows CK7 expression and diffuse AMACR expression.

\section{Immunohistochemistry}

The MCRN-LMP and ccRCC with cystic changes are morphologically indistinguishable. Kim et al studied various tissue markers with differential expression between MCRN-LMP and ccRCC with cystic changes and stated that it can provide a clue to understanding their distinct pathophysiology [11]. They studied the 25 tissue markers, among these only HIFla, PDGFR $\alpha$, SMA, VEGFR1, VEGFR2, VEGFR3, CD10, CD31, CD34, CK7-tubule, TGAse-2, and Ki-67 showed significantly different expression between these groups. The immunoreactivity for cytokeratin 7 is resemble that of clear cell papillary RCC characterized by prominent cystic architecture. However, clear cell papillary RCC is generally negative or focally positive for CD10.

$\mathrm{Yu}$ et al'sstudy showed that MCRN-LMP (reported under MCRCC) is usually positive for CD10, Vimentin, EMA, CA-IX, PAX-2 and stated it will be is helpful for differentiating variable other cystic renal tumors [12].

\section{Genetic and molecular research in MCRN-LMP}

These neoplasms are genetically related to ccRCC. The deletion of chromosome $3 p$ was identified in one third of tumors using FISH analysis and VHL gene mutation was identified in $25 \%$ of MCRNLMP $[13,14]$.

Kim et al [15] studied the tumor tissues from 5 MCRNLMP and 16 ccRCCwith cystic change cases for gene sequencing to detect mutations among 88 genes selected from a kidney cancer gene panel after quality control. The six genes showed a significantly different frequency of mutation between MCRNLMP and ccRCC with cystic change groups: GIGYF2 (odds ratio [OR], 5.735), FGFR3 (OR, 6.787), SETD2 (OR, 4.588), BCR (OR, 6.266), KMT2C (OR, 8.167), and TSC2 (OR, 4.474).

MCRNLMP -Multilocular cystic renal neoplasm of low malignant potential, Ch-Chromosome, miR-microRNA, ACDacquired cystic disease, RCC- Renal Cell Carcinoma. VHL-von Hippel Lindau, Cystic PRCC-Cystic Papillary RCC.

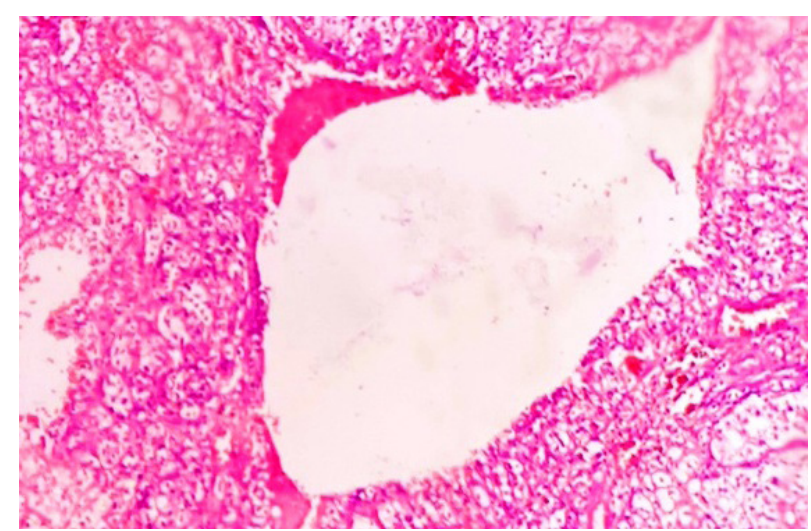

Figure 4. Renal cysts filled with blood, wall showing capillary proliferation, the septa containing tumor of low nuclear grade $(\mathrm{H} \& \mathrm{E}$ Stain, 40x).

\section{Therapy and Prognosis}

Based on the fact that this is tumor with low nuclear grade and confined to the kidney, their survival rate is significantly better than conventional RCC. MCRN-LMP has been classified as a neoplasm with an intrinsically cystic growth pattern, and no, or at most uncertain malignant potential. Accurate diagnosis is always important in a cancer context even the low or uncertain malignant potential of this tumors. The treatment options are either simple nephrectomy or nephron sparing surgery. MCRNLMP usually has an excellent prognosis, nephron sparing surgery is first recommended as a therapeutic strategy. Suzigan et al. in their recent large series of the 45 cases of MCRN-LMPpublished under MCRCC, they found $82 \%$ of their cases in T1 stage and low nuclear grade found in $62 \%$ cases of them. Also Suziganet al in their study showed the 5 -year survival rate was $100 \%$ [16]. This paper has been published in 2006 under the name of MCRCC, but should be MCRN-LMP.

The benign clinical course has been observed by Nassir et al. who defined MCRN-LMP as a cystic lesion with neoplastic clear cells, an uncommon subtype of conventional ccRCC [17].

In difficult situation of distinguishing ccRCC from MCRNLMP, the best morphologic feature is demonstration of presence of expansile growth clear cell in ccRCC. In MCRN-LMP, the expansile growth of clear cells should not be present. The International Society of Urological Pathology, has clearly defined MCRN-LMP as a least aggressive neoplasm with no recurrence and no metastatic potential after surgical treatment [18].

In the future it will probably represent an era of research and application of immune check point inhibitor treatment in renal tumors [19]. As suggested by Li et al. [22] in their study, the nuclear grade of MCRN-LMP cases was unrelated to the tumor size and TNM stage. In their largest published series of 76 cases of MCRN-LMP, 66 patients were followed up for median of 52 months. No recurrence was observed. The treatment of patients with MCRN-LMP were 18 underwent radical open nephrectomy, 18 laparoscopic radical nephrectomy, 22 open partial nephrectomy, and 18 laparoscopic partial nephrectomy.

In another study the 6 cases of MCRN-LMP were reported by Murad et al and they were followed for a minimum of 2 years and noted no recurrence or metastasis was observed. They have concluded that the tumor was a low-grade variant of RCC [20]. Nephron sparing surgery is only advisable to those patients with single kidney or those where contralateral kidney tend to be nonfunctiong in near future [21]. 
The study by Bhatt et al proposed that since postoperative followup protocols are dictated by staging, that for this entity of MCRN-LMP the T staging should be abandoned or reassigned as pT1c to guide clinicians and nonsurgical management when feasible [22]. Also Li T et al. stated that the patients with MCRNLMP have an excellent prognosis, the follow-up interval after surgery can be longer to minimize unnecessary examinations [23]. The study by Alekseev BY et al. showed that patients with MCRCN-LMP have the best oncological prognosis among renal tumors. The necessity of classification of this tumor in accordance with the TNM system is currently dubious. Only organ-preserving surgeries should be used in treatment of the disease [24].

\section{Conclusions}

Multilocular cystic renal neoplasm of low malignant potential is a newer entity. The various modalities are required for it are clinical, histomorphological, radiologic evaluation, and immunohistochemical assay. It will be is useful to differentiate between various cystic renal conditions allowing an accurate diagnosis .

The aim of this review is to bring attention, that MCRN-LPM is a least aggressive neoplasm with no recurrence and no metastatic potential. The updated diagnostic modalities and conservative line of management may be applicable for this rare entity for the better care of patients.

\section{Acknowledgements}

NIL.

\section{Ethical policy}

Approval was taken from institutional ethical committee. The study was performed in accordance with the Declaration of Helsinki. Patients gave their informed consent for their participation.

\section{Author contributions}

SVJ designed the study, drafted the manuscript, searched literature, revised it critically for important intellectual content, read and approved the final manuscript.

\section{Competing interests}

The authors declare no competing interests.

\section{Funding}

NIL.

\section{References}

1. Bernstein J: A classification of renal cysts. Perspect Nephrol Hypertens 1976, 4: 7-30.

2. Katabathina VS, Kota G, Dasyam AK, Shanbhogue AK, Prasad SR: Adult renal cystic disease: a genetic, biological, and developmental primer. Radiographics 2010, 30(6): 1509-1523.

3. Bisceglia M, Galliani CA, Senger C, Stallone C, Sessa A: Renal cystic diseases: a review. Adv Anat Pathol 2006, 13(1): 26-56.

4. World Health Organization, World Health Organization Classification of Tumors: Pathology and Genetics of Tumors of the Urinary System and Male Genital Organs, IARC, Lyon, France, 2004.

5. Moch H, Humphrey PA, Ulbright Thomas M, Reuter Victor E Lyon:
WHO classification of tumours of the urinary system and male genital organs. International Agency for Research on Cancer (IARC) 2016.

6. Han KR, Janzen NK, McWhorter VC, Kim HL, Pantuck AJ, Zisman A, et al: Cystic renal cell carcinoma: Biology and clinical behavior. Urol Oncol 2004, 22(5): 410-414.

7. Kim JC, Kim KH, Lee JW: CT and US findings of multilocular cystic renal cell carcinoma. Korean J Radiol 2000, 1(2): 104-109.

8. Eble JN, Bonsib SM: Extensively cystic renal neoplasms: cystic nephroma, cystic partially differentiated nephroblastoma, multilocular cystic renal cell carcinoma, and cystic hamartoma of renal pelvis. Semin Diagn Pathol 1998, 15(1): 2-20.

9. Nikumbh DB, Jagtap SV, Jain G, Mali RK: Mutlilocular cystic renal cell carcinoma: An unusual gross appearance. OJHAS 2011, 10(1): 17.

10. Zhang W, Li Y, Lu Q, Zhuang J, Wang Q, Zhao H, Yu W, Kang E, Feng Z: Clinicopathologic features and differential diagnosis of multilocular cystic renal cell carcinoma 2014, 43(11): 723-727.

11. Kim SH, Park B, Joo J, Joung JY, Seo HK, Lee KH, Park WS, Chung J: Retrospective analysis of 25 immunohistochemical tissue markers for differentiating multilocular cystic renal neoplasm of low malignant potential and multicystic renal cell carcinoma. Histol Histopathol 2018, 33(6): 589-596.

12. Yu YW, Hou JG, Chen HT, Cao GW, Wang LH, Xu CL, Sun YH: Clinicopathologic features and molecular genetic analysis of multilocular cystic renal cell carcinoma. Zhonghua Bing Li Xue Za Zhi 2008, 37(11): 721-725.

13. von Teichman A, Compérat E, Behnke S, Storz M, Moch H, Schraml P: VHL mutations and dysregulation of pVHL- and PTENcontrolled pathways in multilocular cystic renal cell carcinoma. Mod Pathol. 2011, 24(4): 571-578.

14. Halat S, Eble JN, Grignon DJ, Lopez-Beltran A, Montironi R, Tan $\mathrm{PH}$, et al: Multilocular cystic renal cell carcinoma is a subtype of clear cell renal cell carcinoma. Mod Pathol 2010, 23(7): 931-936.

15. KimSH, Park WS, Chung J: SETD2, GIGYF2, FGFR3, BCR, KMT2C, and TSC2 as candidate genes for differentiating multilocular cystic renal neoplasm of low malignant potential from clear cell renal cell carcinoma with cystic change. Investig Clin Urol 2019, 60(3): 148-155.

16. Suzigan S, López-Beltrán A, Montironi R, Drut R, Romero A, Hayashi T, et al: Multilocular cystic renal cell carcinoma: A report of 45 cases of a kidney tumor of low malignant potential. Am J Clin Pathol 2006, 125(2): 217-222.

17. Nassir A, Jollimore J, Gupta R, Bell D, Norman R: Multilocular cystic renal cell carcinoma: a series of 12 cases and review of the literature. Urology 2002, 60(3): 421-427.

18. Srigley JR, Delahunt B, Eble JN, Egevad L, Epstein JI, Grignon D, Hes O, Moch H, Montironi R, Tickoo SK, Zhou M, Argani P: ISUP Renal Tumor Panel. The International Society of Urological Pathology (ISUP) Vancouver Classification of Renal Neoplasia. Am J Surg Pathol 2013, 37(10): 1469-1489.

19. Zhang P, Ro JY: Renal cell carcinoma. Ann Urol Oncol 2018, 1(1): $1-18$.

20. Murad T, Komaiko W, Oyasu R, Bauer K: Multilocular cystic renal cell carcinoma. Am J Clin Pathol 1991, 95(5): 633-637.

21. Delakas D, Karyotis I, Daskalopoulos G, Terhorst B, Lymberopoulos S, Cranidis A: Nephron-sparing surgery for localized renal cell carcinoma with a normal contralateral kidney: A European threecenter experience. Urology 2002, 60(6): 998-1100.

22. Bhatt JR, Jewett MA, Richard PO, Kawaguchi S, Timilshina N, Evans A, Alibhai S, Finelli A: Multilocular Cystic Renal Cell Carcinoma: Pathological T staging makes no difference to favorable outcomes and should be reclassified. J Urol 2016, 196(5): 1350-1355.

23. Li T, Chen J, Jiang Y, Ning X, Peng S, Wang J, He Q, Yang X, Gong K: Multilocular Cystic Renal Cell Neoplasm of Low Malignant Potential: A Series of 76 Cases. Clin Genitourin Cancer 2016, 14(6): 
e553-e557.

24. Alekseev BY, Shevchuk IM, Efremov GD, Samoylova SI Multilocular cystic renal neoplasm of low malignant potential: experience of N.N. Lopatkin Scientific Research Institute of Urology and Interventional Radiology. Cancer Urology 2017, 13(3): 34-38. 